\title{
The Comparative Effect of Top-down Processing and Bottom- up Processing through TBLT on Extrovert and Introvert EFL Learners' Reading Comprehension
}

\author{
Pezhman Nourzad Haradasht (Corresponding Author) \\ Foreign Language Faculty, Central Tehran Branch, IAU, Tehran, Iran \\ E-mail: Pnoorzad@yahoo.com \\ Abdollah Baradaran \\ Foreign Language Faculty, Central Tehran Branch, IAU, Tehran, Iran \\ E-mail: baradaranabdollah@yahoo.com
}

Received: 09-06-2013

doi:10.7575/aiac.ijalel.v.2n.5p.229
Accepted: 14-07-2013

Published: 01-09-2013

URL: http://dx.doi.org/10.7575/aiac.ijalel.v.2n.5p.229

\begin{abstract}
This research seeks to examine the effect of two models of reading comprehension, namely top-down and bottom-up processing, on the reading comprehension of extrovert and introvert EFL learners' reading comprehension. To do this, 120 learners out of a total number of 170 intermediate learners being educated at Iran Mehr English Language School were selected all taking a PET (Preliminary English Test) first for homogenization prior to the study. They also answered the Eysenck Personality Inventory (EPI) which in turn categorized them into two subgroups within each reading models consisting of introverts and extroverts. All in all, there were four subgroups: 30 introverts and 30 extroverts undergoing the top-down processing treatment, and 30 introverts and 30 extroverts experiencing the bottomup processing treatment. The aforementioned PET was administered as the post test of the study after each group was exposed to the treatment for 18 sessions in six weeks. After the instructions finished, the mean scores of all four groups on this post test were computed and a two-way ANOVA was run to test all the four hypotheses raise in this study. the results showed that while learners generally benefitted more from the bottom-up processing setting compared to the top-down processing one, the extrovert group was better off receiving top-down instruction. Furthermore, introverts outperformed extroverts in bottom-up group; yet between the two personalities subgroups in the top-down setting no difference was seen. A predictable pattern of benefitting from teaching procedures could not be drawn for introverts as in both top-down and bottom-up settings, they benefitted more than extroverts.
\end{abstract}

Keywords: Reading comprehension, top-down processing, bottom-up processing, extrovert, introvert

\section{Introduction}

People like to read more and more and teacher uses this opportunity to encourage learners to choose for themselves what they read and they are also encouraged to do the reading for pleasure and general language improvement which is called extensive reading (Harmer, 2008). However, others read to find and understanding specific information given in the text which is called intensive reading (Harmer, 2008).

There have been different objectives among EFL learners towards reading comprehension. One of the major objectives of reading comprehension is upgrading students' ability to simultaneously read the words and comprehend what they mean. Reading a text means both reading and understanding it (Ur, 1996). In this sense reading does not mean translating written symbols into corresponding sounds. Barnett maintains that reading is seen "as communication, as a mental process, as the readers' active participation in the creation of meaning, as a manipulation of strategies, as a receptive rather than passive skill" (2007, p. 71).

All those who are involved in the field of language teaching, whether they are working on reading or any other skills, have one purpose in mind and that is to ease the process of teaching for themselves and learning for learners. Therefore, teachers' knowledge in the last few years towards the importance of knowing more about learners' differences, characteristics, personality types, and psychological effects has been increased. Learner factors namely age, aptitude, attitude, motivation, personality, cognitive styles, and preferred learning strategies must be taken into consideration in any comprehensive theory at L2 acquisition (Hadley, 2003). Therefore, a person may have different personality type; however, regarding what type of personality type best suit them in that very case of learning, they decide to utilize the best one through modifying the most appropriate one. Hence, in order to facilitate learning through the use of certain strategies, more effective ones should be modified (Hedge, 2008).

The personality type that has attracted the most attention in L2 research is extroversion/introversion (Dornyei, 2005). Extroverts and introverts can learn to work with each other while the teacher is helping them in that the person in charge of leading the L2 discussion gives introverts an opportunity to participate equally with extroverts (Celce-murcia, 2001). 
Despite the existence of different personality variables affecting L2 learning, one cannot ignore the role of models to learning a new skill. One of those models is top-down and bottom-up processing models in comprehending a reading text. In top-down processing, the reader gets a general view of the reading by absorbing the overall picture (Harmer, 2008). In bottom-up processing, meaning exists in the text itself by stringing the words, phrases, cohesive devices together (Ajideh, 2003).

These two models should be applied in reading comprehension, here through the administration of tasks. A task is a type of activity in which learners are required to utilize language, while putting emphasis on meaning, in order to obtain a goal (Bygate, Skehan, and Swain, 2001, cited in Ellis, 2003).

The present study aims to explore the comparative influence of top-down processing and bottom-up processing models accompanied with tasks for the reading comprehension of extroverts and introverts. Based on the crucial importance of comprehension, the selected tasks are according to either top-down or bottom-up processing model. The Following listed tasks are top-down processing in which students will get a general overview of the text:

1. Paraphrasing: in this task students should retell what they have grasped with the same meaning but with different structure

2. Using background knowledge and experience: what students have about the past about the title or thesis of the text is considered students' background knowledge which must be activated.

3. Prediction: here, some key words out of the text and/or the title of the text are put on the board for the student to see and predict what they will encounter whole through the reading text.

4. Note taking: in this task students should read the text silently for themselves and take notes from what they consider the gist.

There exist other tasks considered bottom-up processing tasks in which students analyze the text in detail to achieve comprehension:

1. Using an L1 or an L2 equivalent: this task is about the unknown words students do not know the meaning. thereby, they should apply an L1 or an L2 equivalents

2. Scanning for unfamiliar words: here, the eyes are just looking for the words deemed unknown

3. Through which they can comprehend the text.

4. Rereading: in this way students should read the parts they could not get again and again to find some clues for easing the comprehension

5. Marking the text: there are some parts in every text that should be marked or underlined for the sake of later comprehension or spending some time on it to analyze in detail.

According to afore-mentioned points the following research questions were formulated:

Q1. Is there any significant difference between the effect of top-down and bottom-up processing through TBLT on introvert EFL learners' reading comprehension?

Q2. Is there any significant difference between the effect of top-down and bottom-up processing Through TBLT on extrovert EFL learners' reading comprehension?

Q3. Does top-down processing through TBLT have a significantly different impact on the reading comprehension of introvert and extrovert EFL learners?

Q4. Does bottom-up processing through TBLT have a significantly different impact on the reading comprehension of introvert and extrovert EFL learners?

\section{Review of the related literature}

\subsection{Reading comprehension}

Reading is not only reading a simple text but it is both the extraction and construction of meaning through interaction and involvement with written language which require the reader, the text, and the activity or the purpose for reading (Snow, 2002).

Reading comprehension is of paramount importance. According to Richards and Renandya (2002), reading has gathered the attention of many experts, researchers, learners because of a number of reasons:

- Firstly, Reading is one of the most crucial aims of foreign language learners because in this way they can read for knowledge, for their career, and for educational purposes.

- Secondly, reading texts is considered as pedagogical purposes because linguistic exposure to rich text not only increases the speed of language acquisition but also expose them to good writing samples.

- Thirdly, it also gives students time to be familiar with new points of discussion, to encourage speaking and to work on other skills such as vocabulary, grammar, idioms.

When we read a text, we don't solely read the lines with some words. As Grabe (2004, p19) suggested that "reading comprehension implies processing efficiency, language knowledge, strategic awareness, extensive practice in reading, cognitive resources in working memory to allow critical reflection, and appropriate purposes for reading".

Roe, Smith \& Burns (2005) stated that if one wants to understand the reading text completely, he must use the clues in the text for inferential understanding and creative and critical reading, which means figuring out literary terms, deciding the author's intention, evaluating the stated views and putting those views in real conditions. 
Reading processes have been categorized as data-driven processes in which reader should have sophisticated knowledge of language itself and conceptually-driven approach in which he draws on his intelligence and experience to understand a text (Brown, 2001).

According to Abbot (2007, p.15) "Some of the binary reading strategies include bottom-up vs. top-down, local vs. global, data driven vs. concept driven, form based vs. meaning based, syntactic vs. semantic, decoding vs. meaninggetting, language-based vs. knowledge-based, word-level vs. text-level, micro vs. macro, analytic vs. synthetic, and analytic vs. global".

\subsubsection{Top-down Processing}

Top-down processing wants readers to administer the background knowledge before and during the reading process, through the existent clues in the text, in order to check if their previous knowledge was according to what they believed. (Eskey, 2005).

According to Nunan (2001) in top-down processing or psycholinguistic approach to reading, one begins with a series of hypotheses or predictions about the concept of the text one is about to read, and then selectively samples the text to determine whether or not one's predictions are correct.

Nuttal (1998) compared top-down processing to an eagle eye's view of the landscape in which an eagle was able to take a look at the expanded landscape from distant point of sky and this way it can have a general pattern between various parts of something that an observer on the ground cannot have

According to Birch(2007), "As we learn to decode, we also learn a large set of strategic reading skills, which we will call top-down skills and strategies, that readers use in concert with background knowledge to construct meaning from the text (p. 33).

Therefore, top-down processing model to reading is a process one begins with the largest elements and works down towards smaller elements to build comprehension of what is being read.

\subsubsection{Bottom-up Processing}

In bottom-up reading processing, readers need visual sense, contrary to bottom-up listening processing in which listeners need auditory sense, to process written syntax (for example, word order), lexicon (the words and the meaning of words), orthography (letters), decode words as well as have an ability to process reading phonology (for example, the intonation used in reading when we read aloud inside our heads or to an audience) (Gebhard, 2009).

Nuttal (1998) considered bottom-up processing as the picture of a scientist holding a magnifying glass and testing the ecology of a transect which is the small bit of the landscape an eagle looks at. In this illustration, the scientist understood that single piece of area in detail which is probably taken as a sentence in the context of reading.

Gladwin and Stepp-Greany (2008) stated that teaching reading in accordance with bottom-up views included activities such as making the text simple, developing vocabulary, exploring words and structures in detail, rereading the text, and responding comprehension questions_basically teacher-centered class activities.

According to Rupp, Ferne and Choi (2006, p.444) "In order to highlight the importance of the efficiency and accuracy of bottom-up skills, the term 'Matthew Effect' was coined to represent the notion that automaticity of lower level reading skills, in particular phonological awareness and word recognition skills, are crucial to the future development of successful reading comprehension".

Therefore, bottom-up approach to reading is a process with which the reader begins the smallest elements and builds up to comprehension of what is being read.

\subsection{Personality Traits}

According to Chamorro-Premuzic (2007), traits represent implicit connection between noticeable behaviors and internal dispositions or preferences to act, theses associations picture the individual's unchanging patterns of behavior and delineate differences between rather than within individuals, this in turn may lead to various types of feelings, thinking, and behaving in different ways and among different people.

Personality can be defined in two different ways (a) a number of qualities characterizing an individual, or as (b) the subjacent system that brought on the set of attributes (Boyle, Mathews, \& Saklofske, 2008).

Eysenck 1967 (cited in Singh, 2005, p. 126) "identifies the major component of personality as a small number of personality types. Each type includes a set of personality features. For instance, people who are considered as an extrovert according to Eysenck extroverted type are believed to have characteristics such as sociability, liveliness, and excitability."

The studies have revealed that the most eye-catching personality dimension attracting and prompting researchers' focus in the L2 field has always been extroversion/introversion (Dorneye, 2005).

\subsubsection{Extroversion}

"Extroverted is the extent to which a person has a deep-seated need to receive ego enhancement, self-esteem, and a sense of wholeness from other people whereas introverted receives that affirmation within oneself" (Brown, 2000, p. 166)

"A person whose conscious interaction is more often directed towards other people and events than towards the person themselves" is considered an Extrovert (Richards \& Schmidt, 2002, P. 195). 
According to Eysenck Personality Inventory (EPI) which was administered in this research to rate extroversion/introversion position of the participants, extroverts are bored as time passes by and therefore they need to be encouraged by the external causes to perform optimally outside of their context. Those whose scores were 13 or more on the EPI were considered extroverts.

\subsubsection{Introversion}

"A person who tends to avoid social contact with others and is often preoccupied with his feelings, thoughts, and experience" is considered an introvert (Richards \& Schmidt, 2002, p. 195).

Introverts are more interested in activities such as reading, writing, and drawing than activities which require them to act in an outgoing way (Naik, 2010).

According to the Eysenck, introvert learners are anxious as time elapses and therefore they need calmness and do not want to be interfered by the others to perform optimally. Those whose scores were 12 or less on the EPI were considered introverts.

\section{Method}

This study deals with comparing two models of learning, namely top-down and bottom-up processing, in regards with their effect on reading comprehension of introvert and extrovert EFL learners. To conduct the research, a questionnaire of 57 questions called Eysenck Personality Inventory (EPI) was given to all participants. The design of the study is experimental posttest only as random assignment of four groups took place at the outset of each treatment phase. In order to clarify how the researcher found the answers to the research questions of this study, all that was conducted throughout the process with detailed information on participants, instrumentation, treatment, are discussed in this part.

\subsection{Participants}

To fulfill the objectives of this study, 120 male intermediate EFL learners with the age range of 16-35 studying in Tehran's Iran Mehr Language School participated in this study. These participants were selected through a proficiency test, PET (Preliminary English Test) from 170 learners in the same language school. Therefore, the number of selected participants for the sake of study was120 students. Because of the number of the participants, the treatments were conducted in two terms. The participants' selection procedures were also done at the beginning of each term meaning that the PET was administered to 90 learners at the outset of the first term through which 60 learners were chosen. Then, they underwent EPI, 30 introverts and 30 extroverts, and the first phase of the treatment was commenced. At the beginning of the second term, the above procedure was conducted again among 80 different learners, 60 of whom were selected for the second phase.

\subsection{Instrument}

To accomplish the objectives of this study, two PETs and a questionnaire were administered. Moreover, certain materials were also used in the teaching procedure throughout the both terms. The first PET was used for homogenization process prior to the treatment. The second administration of the test was when the treatment was completed. Therefore, The PET was used this time as the post test after the course. EPI questionnaire was to assess the personality traits of the participants. This hugely validates test consists of 57 Yes/No items. he scores given to those who fill out the questionnaire were: the E score computed out of 24 is related to how much extrovert a person is, the $\mathrm{N}$ score measuring the neuroticism is also out of 24 , and the Lie score which tries to measure how socially desirable a person has wanted to prove to be is out of 9 . The following materials as course books of this study were applied in this research:

\subsubsection{Preliminary English Test (PET)}

As noted earlier, the PET was used for the homogenization process before the treatment starts and the same test was used as the posttest after the course. The test adopted from PET practice tests by Jenny Quintana, Oxford University Press. The test consisted of two papers: paper 1 for reading / writing and paper 2 for listening. Each part of the test (reading, writing, and listening) consisted of $25 \%$ of the total score which was 75 . The speaking part of the test was not possible to conduct because of two reasons: firstly, it required a qualified examiner from Cambridge ESOL exams. Secondly, it was not the focus of the current study.

The reading part of the test consisted of 35 items, writing 7 items (including two writing tasks), and the listening 25 items and the administration of the whole test took 120 minutes.

This test revealed appropriate items for and characteristics for the sample since it was piloted with 30 participants with the students of the same language school, having similar characteristics as the target sample before the actual administration.

3.1 Descriptive Statistics of PET Piloting

\begin{tabular}{lrrrrr}
\hline & $\mathrm{N}$ & Minimum & Maximum & Mean & \multicolumn{1}{c}{ Std. Deviation } \\
\hline PET Piloting & 30 & 32.00 & 63.00 & 43.5000 & 8.72076 \\
\hline Valid N (listwise) & 30 & & & & \\
\hline
\end{tabular}

3.2 Reliability of the PET Piloting

\begin{tabular}{cc}
\hline Cronbakh's Alpha & N of Items \\
\hline .8 & 67 \\
\hline
\end{tabular}




\subsubsection{Eysenck Personality Inventory (EPI)}

In the EPI, the personality traits of a person are assessed. It was designed by the German psychologist Hans Jurgen Eysenck and his wife Sybil B. G. Eysenck. Eysenck firstly pictured personality as two categories of biologically-based temperament which include: extroversion/introversion and neuroticism/stability. This hugely validated test consists of $57 \mathrm{Yes} /$ No items. Those who fill out the EPI receive three different kinds of scores: the E score which is related to how much extrovert a person is, the $\mathrm{N}$ score measuring the neuroticism, and the Lie score which tries to measure how socially desirable a person has wanted to prove to be. The E score is computed out of 24 because it consists of 24 items, the $\mathrm{N}$ score is out of 24 , and the Lie score is out of 9 .

The Yes/No answers should be given based on the usual way of acting or thinking of an individual. The researcher used the Farsi version provided and validated by Noor institute of Behavioral Sciences Research in Tallish in order for the respondents to answer the questionnaire more accurately. The answer key and the standard rating scales were also provided in the battery.

\subsubsection{Materials}

\subsubsection{Interchange $3,3^{\text {rd }}$ edition}

The main text book used in this research was interchange 3 by Jack C. Richards with Jonathan Hall and Susan Proctor. This textbook was used in Iran Mehr Language School for intermediate learners and it consists of 16 units which are divided into four terms. The main purpose of this book is to integrate reading, grammar, pronunciation, vocabulary, listening, speaking, and writing. Every units of this book also contains reading comprehension text.

\subsubsection{Oxford Word Skills}

This is a series of three books for students to learn, practice, and revise new vocabulary developed by Gairns and Redman. It is available in basic, intermediate, and advanced level. Each unit contains 80 units of vocabulary presentation and practice. The intermediate level includes the following: 1) various topics in real life, e.g. foods, communication, friendship; 2) Words and phrases needed in social interaction, e.g. giving opinions and making arrangements to meet; and 3) Areas of lexical grammar, e.g. word formation, suffixes and prefixes, and connectors.

\subsubsection{Selected Reading Books}

These books contain reading pages of different genres and are graded from elementary to upper-intermediate level, using the syllabus devised by Linda Lee and Eric Gundersen. Since the level of students in this study is intermediate, intermediate level was chosen.

\subsection{Procedure}

In order to conduct this study, the researcher first conducted the PET among 90 intermediate learners for choosing 60 learners whose scores on the test fell one standard deviation above and below the mean. In the first phase of the study the bottom-up processing model was administered. In the next step, EPI was conducted among 60 participants dividing them into 30 introverts and 30 extroverts.

In the first phase of the study, with two types of learners namely extroverts and introverts, the teacher tried to implement some tasks that were bottom-up. The researcher implemented the following bottom-up processing tasks to see how they can contribute the learners' reading comprehension: using an L1 or an L2 equivalent, scanning for unfamiliar words, rereading, and marking the text.

After each reading texts of the main book, there are some questions such as short answer, true false, and some teacher designed multiple choice questions. The students were told to read the text for themselves and then reread it. After that they should underline the parts they could not understand. Next, through finding an L1 or an L2 equivalent, they should process their comprehension. In the listening part, the script was given to students. They were looking at the text while the listening track was being played. They were required to mark the parts they did not understand for the later interpretation.

Oxford Word Skill was the vocabulary book with some short reading texts. Students were responsible for reading each part and translating the meaning of words either in L1 or in L2 in case they face with some unfamiliar ones. Having analyzed every single detail, they should retell each other what they had understood.

Immediately after this treatment, the first group of the study which was practicing English, specifically reading comprehension, with a bottom-up processing model underwent the posttest to see how the treatment could significantly affect students' comprehension.

The subsequent term, the same participant selection procedure was conducted again with 80 learners undergoing the PET, 60 of whom were chosen and subsequently sat for the EPI. This time, students received top-down processing model. The teacher started to apply top-down processing tasks to see in what way they can help the learners comprehend the text. The following tasks were administered: paraphrasing, using background knowledge and personal experience, prediction, note taking.

The same materials were taught but with the other model, top-down processing this time. The teacher elicited some of the key words of the text and put them on the board accompanied with the title of the text. Then, the teacher got the students to predict what they would see in the text according to the given information on the board. Sometimes the teacher asked some questions to activate students' background knowledge or schemata. 
Oxford Word Skill was practiced in another way. One of the students was asked to read half of its reading part. The other should take notes about what they understood from his reading. Finally, students who were note takers were responsible for predicting what will happen in the second half according to their notes.

The students were asked to study one unit of the selected reading book at home. First, they had to read it once to take the whole and general idea of the text. Second, they had to paraphrase it in the L2 language. In some sessions, the students were required to summarize what they read at home by taking notes and present what they have summarized by taking look at their notes.

This group also underwent the PET as the posttest of the study at the end of the 18 sessions of top-down processing model.

\section{Data Analysis}

To verify all four hypotheses of the study together, a two-way ANOVA was required since there is a dual learning modality (top down versus bottom up learning) and also a dual style of personality (extroverts and introverts) involved with one dependent variable (reading comprehension) at stake (Table 4.5).

\section{Results and Discussion}

The statistical procedure of the study was based on a two-way ANOVA procedure which was run to study the interaction of two modalities of the independent variable and the two moderator variables on the dependent variable of this study.

\subsection{Descriptive Statistics of the 170 students taking the PET Prior to the Study Following the piloting}

The PET was administered among 170 students so that the researcher could select the 120 learners required for this study. Table 4.1 displays the descriptive statistics of the scores of the 170 students who sat for the PET prior to the selection of participants.

Table 4.1 Descriptive Statistics of the 170 Students Who Took the PET Prior to the Study

\begin{tabular}{lrrrrr}
\hline & N & Minimum & Maximum & Mean & Std. Deviation \\
\hline PET Administration & 170 & 25.00 & 67.00 & 44.6353 & 9.14298 \\
\hline Valid N (listwise) & 170 & & & & \\
\hline
\end{tabular}

As displayed in the table above, the mean and standard deviation were 44.64 and 9.14, respectively.

\subsection{Descriptive Statistics of 120 Participants in the Four Groups Prior to the Study}

Among the above 170, a total of 120 whose scores fell one standard deviation above and below the mean were selected. Table 4.2 displays the descriptive statistics of these 120 participants.

Table 4.2 Descriptive Statistics of the 120 Participants in the Four Groups Prior to the Study

\begin{tabular}{lrrrrr}
\hline & N & Minimum & Maximum & Mean & Std. Deviation \\
\hline $\begin{array}{l}\text { Participants Scores Prior } \\
\text { To The Study }\end{array}$ & 120 & 35.00 & 50.00 & 43.0833 & 2.83016 \\
\hline Valid N (listwise) & 120 & & & & \\
\hline
\end{tabular}

Following the above selection, the 120 students were randomly assigned into four experimental groups including 30 students in each of the groups (as detailed in the previous chapter). Having finalized the participants' selection process, the teacher-researcher began the four different treatments in each group (detailed in the previous chapter).

\subsection{Descriptive Statistics of All Four Groups on the Posttest}

Following the treatment, the researcher administered the aforementioned posttest to all four groups. This section details the descriptive statistics of the administration of this posttest.

Table 4.3 below displays the descriptive statistics for all four groups on the posttest in one table for easier reference.

Table 4.3 Descriptive Statistics of All Four Groups on the Posttest

\begin{tabular}{lccccrrr}
\hline & $\mathrm{N}$ & Minimum & Maximum & Mean & Std. Deviation & \multicolumn{2}{c}{ Skewness } \\
\hline & Statistic & Statistic & Statistic & Statistic & Statistic & Statistic & Std. Error \\
\hline $\begin{array}{l}\text { Extrovert_- } \\
\text { Top Down }\end{array}$ & 30 & 12.00 & 30.00 & 22.9000 & 4.97130 & -.568 & .427 \\
\hline $\begin{array}{l}\text { Extrovert_- } \\
\text { Bottom Up }\end{array}$ & 30 & 12.00 & 30.00 & 20.9333 & 5.07144 & .118 & .427 \\
\hline $\begin{array}{l}\text { Introvert_ } \\
\text { Top Down }\end{array}$ & 30 & 12.00 & 32.00 & 22.9000 & 5.57921 & -.186 & .427 \\
\hline $\begin{array}{l}\text { Introvert_ } \\
\text { Bottom Up }\end{array}$ & 30 & 17.00 & 35.00 & 28.0000 & 5.02408 & -.454 & .427 \\
\hline Valid N (listwise) & 30 & & & & & & \\
\hline
\end{tabular}


Figures 4.1, 4.2, 4.3, 4.4 below display the descriptive statistics for a clear visual understanding

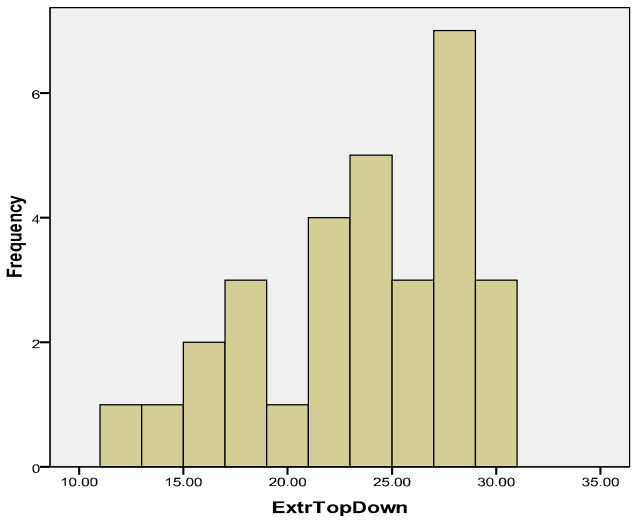

Mean $=22.90$
Std. $D$ Dev
$N=30.971$

5.1 Descriptive Statistics of the Scores in the Extrovert Top-down Group on the Posttest

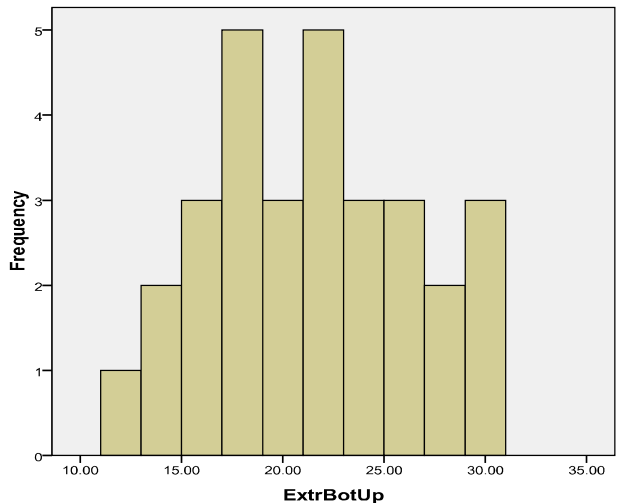

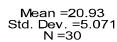

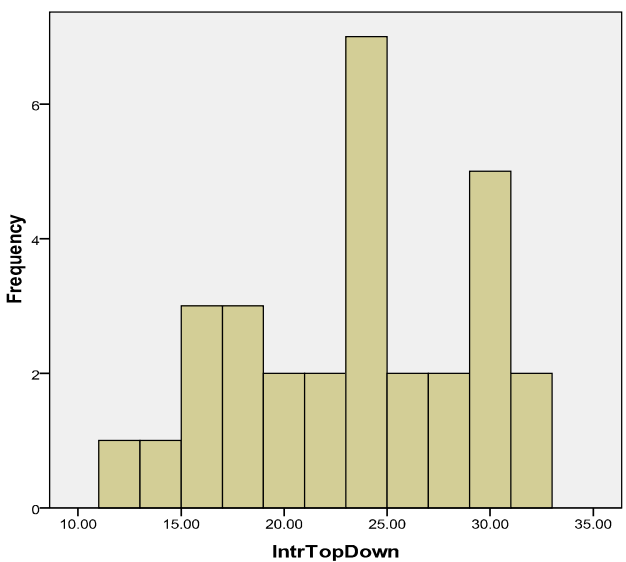

Mean $=22.90$
Stc. Dov
$N=30.579$

5. 3 Descriptive Statistics of the Scores in the Introvert Top-down Group on Posttest

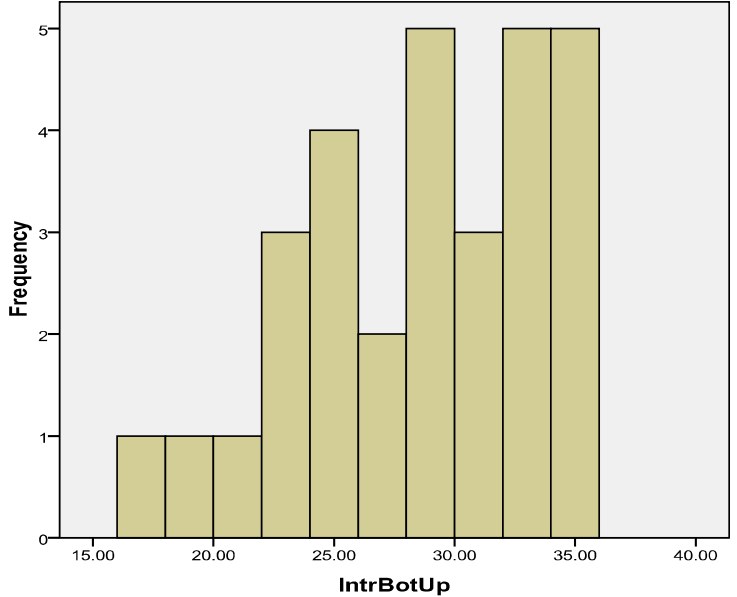

Mean $=28.00$
std. Dev
$N=30.024$

5.4 Descriptive Statistics of the Scores in the Introvert Bottom-up Group on the Posttest 
The following table states the reliability of the PET administration in the posttest, as it shows in the table 4.4

Table 4.4 Reliability of the PET Administration as Posttest

\begin{tabular}{cc}
\hline Cronbach's Alpha & N of Items \\
\hline .824 & 35 \\
\hline
\end{tabular}

Table 4.5 Between-Subjects Factor

$\frac{\text { Personality }}{\text { Extroverts (1) Introverts (2) }}$

\begin{tabular}{lccc}
\hline \multirow{2}{*}{ Learning mode } & Top down (1) & 30 & 30 \\
\cline { 2 - 4 } & Bottom Up (2) & 30 & 30 \\
\hline
\end{tabular}

Prior to this of course, the two assumptions for running this parametric test had to be checked. Firstly, the descriptive statistics of all four subgroups had to be checked for normality of distribution. As is evident from Table 4.5 above, the skewness ratios of all four subgroups fell within the acceptable range of \pm 1.96 .

Next was checking the Levene's test of equality of error variances. Table 4.6 below shows that the variances among the four subgroups were not significantly different $\left(F_{(3,116)}=0.153, p=0.927>0.05\right)$.

Table 4.6 Levene's Test of Equality of Error Variances

\begin{tabular}{rrrr}
\hline F & df1 & \multicolumn{1}{c}{ df2 } & \multicolumn{1}{l}{ Sig. } \\
\hline .153 & 3 & 116 & .927
\end{tabular}

Tests the null hypothesis that the error variance of the dependent variable is equal across groups

a. Design: Intercept + Group

Accordingly, running a two-way ANOVA was legitimized. Table 4.7 below shows the results of the tests of betweensubjects effects

Table 4.7 Tests of Between-Subjects Effects

\begin{tabular}{lrrrrr}
\hline Source & $\begin{array}{c}\text { Type III Sum } \\
\text { of Squares }\end{array}$ & df & Mean Square & F & Sig. \\
\hline Corrected Model & $822.700^{\mathrm{a}}$ & 3 & 274.233 & 10.271 & .000 \\
\hline Intercept & 67308.033 & 1 & 67308.033 & 2520.846 & .000 \\
\hline Learning Mode & 374.533 & 1 & 374.533 & 14.027 & .000 \\
\hline Personality Type & 374.533 & 1 & 374.533 & 14.027 & .000 \\
\hline $\begin{array}{l}\text { Learning Mode } * \\
\text { Personality Type }\end{array}$ & 73.633 & 1 & 73.633 & 2.758 & .099 \\
\hline Error & 3097.267 & 116 & 26.701 & & \\
\hline Total & 71228.000 & 120 & & & \\
\hline Corrected Total & 3919.967 & 119 & & & \\
\hline
\end{tabular}

a. R Squared $=.210$ (Adjusted R Squared $=.189)$

As Table 4.7 indicates, the significance value was less than $0.05\left(F_{(3,116)}=822.700, p=0.000\right)$. There was a significant difference between the impact of the two learning modes on all the participants $\left(F_{(1,116)}=374.533, p=0.000<0.05\right)$. Furthermore, there was a significant difference between the impact of the two personality types in this study in general $\left(F_{(1,116)}=374.533, p=0.000<0.05\right)$. Finally, as the interaction of the learning mode and personality type did not prove significantly different $\left(F_{(1,116)}=73.63, p=0.099>0.05\right)$, the overall conclusion was that the interaction of the two learning modes (top down and bottom up) with the two personality types (extroverts and introverts) was not significant.

As in this univariate two-way ANOVA, there were only two modalities of each of the pair of variables, running PostHoc tests was not feasible since a minimum of three cases are required for such tests. Hence, as the differences proved significant, the researcher had to clarify which group significantly outperformed which through a two-by-two comparison.

The first step was to calculate the descriptive statistics for each of the following groups on the posttest: the 60 participants who underwent top down learning in both groups, the 60 participants who underwent bottom up learning in both groups, the 60 participants who were extroverts, and the 60 participants who were introverts. 
Table 4.8 displays the results for the two overall groups top down and bottom up learning.

Table 4.8 Descriptive Statistics for Learning Mode on the Posttest

\begin{tabular}{|c|c|c|c|c|c|}
\hline \multicolumn{4}{|c|}{ Learning Type } & \multirow{2}{*}{$\begin{array}{c}\text { Statistic } \\
22.90\end{array}$} & \multirow{2}{*}{$\begin{array}{c}\text { Std. Error } \\
.804\end{array}$} \\
\hline Posttest & \multirow{3}{*}{ 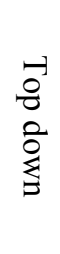 } & Mean & & & \\
\hline & & \multirow{2}{*}{$\begin{array}{l}95 \% \text { Confidence } \\
\text { Interval for Mean }\end{array}$} & Lower Bound & 35.02 & \\
\hline & & & Upper Bound & 38.24 & \\
\hline & \multirow{3}{*}{ 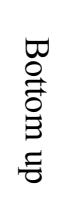 } & Mean & & 24.47 & 1.052 \\
\hline & & \multirow{2}{*}{$\begin{array}{l}95 \% \text { Confidence } \\
\text { Interval for Mean }\end{array}$} & Lower Bound & 26.51 & \\
\hline & & & Upper Bound & 30.72 & \\
\hline
\end{tabular}

Table 4.8 shows that the means for the bottom up group was higher than that of the top down group (24.47 compared to 22.90). Therefore, the bottom up group outperformed the top down group significantly.

Table 4.9 displays the results for the two overall groups of personality types.

Table 4.9 Descriptive Statistics for Personality Type on the Posttest

\begin{tabular}{|c|c|c|c|c|c|}
\hline \multicolumn{4}{|c|}{ Learning Type } & \multirow{2}{*}{$\begin{array}{c}\text { Statistic } \\
21.92\end{array}$} & \multirow{2}{*}{$\begin{array}{c}\text { Std. Error } \\
.988\end{array}$} \\
\hline Posttest & \multirow{3}{*}{$\begin{array}{l}\frac{1}{x} \\
x \\
00 \\
0 \\
0 \\
\frac{1}{4}\end{array}$} & Mean & & & \\
\hline & & \multirow{2}{*}{$\begin{array}{l}95 \% \text { Confidence } \\
\text { Interval for Mean }\end{array}$} & Lower Bound & 27.02 & \\
\hline & & & Upper Bound & 30.98 & \\
\hline & \multirow{3}{*}{$\begin{array}{l}\vec{\Xi} \\
\stackrel{0}{0} \\
0 \\
0 \\
\frac{1}{\infty}\end{array}$} & Mean & & 25.45 & .937 \\
\hline & & \multirow{2}{*}{$\begin{array}{l}95 \% \text { Confidence } \\
\text { Interval for Mean }\end{array}$} & Lower Bound & 34.38 & \\
\hline & & & Upper Bound & 38.12 & \\
\hline
\end{tabular}

Table 4.9 shows that the means for the introverts was higher than that of the extroverts (25.45 compared to 21.92). Therefore, introverts outperformed extroverts.

For further analysis of the ANOVA results and to verify each of the four hypotheses of this research, the means of the four subgroups on the posttest (already shown in Table 4.3) are presented again below in Table 4.10 for easier reference.

Table 4.10 Means of All Four Subgroups on the Posttest

\begin{tabular}{|c|c|c|c|c|}
\hline $\begin{array}{l}\text { Learning mode * } \\
\text { Personality type }\end{array}$ & 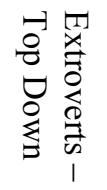 & 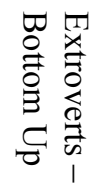 & 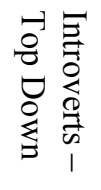 & 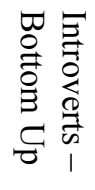 \\
\hline Mean & 22.90 & 20.93 & 22.90 & 28.00 \\
\hline
\end{tabular}

Based on the ANOVA table revealing the significant differences, the first hypothesis of the study, that is, there is no significant difference between the effect of top-down and bottom up processing through TBLT on extrovert EFL learners' reading comprehension was rejected as the extroverts exposed to top down processing outperformed significantly those exposed to bottom up processing.

The second hypothesis which read there is no significant difference between the effect of top-down and bottom up processing through TBLT on introvert EFL learners' reading comprehension was also rejected as the introverts exposed to bottom up processing outperformed significantly those who received top down processing. 
The third hypothesis which states that bottom up processing through TBLT does not have a significantly different impact on extrovert and introvert EFL learners' reading comprehension was also rejected as again introverts outperformed extroverts significantly.

Finally, the fourth hypothesis or top down processing through TBLT does not have a significantly different impact on extrovert and introvert EFL learners' reading comprehension, was not rejected, however, as both subgroups undergoing the top-down treatment gained the same mean score on the posttest

In the next step, the researcher calculated the parameter estimates to estimate eta squared $\left(\eta^{2}\right)$ to find out to what extent the observed difference could be described by the two different learning modes of incidental and intentional vocabulary learning and also the word presentation in semantically related and unrelated sets. Table 4.11 provides that information.

Table 4.11 Estimates of Effect Size for the Posttest

\begin{tabular}{lccc}
\hline Source & $\begin{array}{c}\text { Partial Eta } \\
\text { Squared }\end{array}$ & $\begin{array}{c}\text { Noncent. } \\
\text { Parameter }\end{array}$ & $\begin{array}{c}\text { Observed } \\
\text { Power }^{\mathrm{b}}\end{array}$ \\
\hline Intercept & .836 & 24.274 & 1.000 \\
\hline Learning Mode & .112 & 3.823 & .966 \\
\hline Personality Type & .173 & 4.933 & .998 \\
\hline Learning Mode * Personality Type & .018 & 1.474 & .310 \\
\hline a. R Squared = 0.433 (Adjusted R Squared =0.418) & & & \\
b. Computed using alpha $=0.05$ & & & \\
\end{tabular}

As demonstrated in Table 4.11, $\eta^{2}$ came out to be 0.112 and 0.173 which indicated that the two settings of learning accounted for $11 \%$ of the variability in the posttest scores while the two personality types did so for $17 \%$ of the variability.

Moreover, to determine the strength of the findings of the research, that is, to evaluate the stability of the research findings across samples, effect size was also estimated. The observed power as shown in Table 4.11, came out to be 0.97 for the learning mode and 1.00 for the personality type. According to Mackey and Gass (2005), a value of 0.8 and more is generally considered a large effect size. Therefore, the findings of the study could be considered strong enough for the sake of generalization.

\section{Conclusion}

While many studies portray that it is absolutely wrong to say which one of the reading comprehension models (topdown or bottom-up) for comprehension is better than the other (Mc Neil, 1992) and also other studies (e.g. Farstrup, 2002) show it is worth mentioning that the best language readers are those who can efficiently integrate both top-down and bottom-up processes (albeit the personality factor was not included), this study did prove that the bottom-up processes within introvert group is more advantageous.

At first sight, one might think that the results delineated a contrary corollary to the above statement and that bottom-up processing proves more efficient than top-down processing since those undergoing the bottom-up processing performed better than those in the top-down setting (with mean scores of 24.46 and 22.90, respectively).

Yet, this result is not the categorical finding of this research as albeit the students in the bottom-up group were more successful than those in the top-down group, the extroverts in the top-down group achieved more than the extroverts in the bottom-up group. Hence, while bottom-up teaching was more beneficial to the learners in all, the extrovert group was better off receiving top-down instruction. The reason for this is perhaps due to the very nature of extroverts who seem to be more apt at engaging with one another in group activities.

The above conclusion is further substantiated by the other finding of this research: introverts outperformed extroverts in the bottom-up group meaning that bottom-up processing does not match the personality of extroverts. Thus, it is clear according to this study that extroverts do not benefit all that much from bottom-up processing.

As for introverts, a predictable pattern of benefitting from teaching procedures could not be drawn as introverts in both top-down and bottom-up processing settings benefitted more than extroverts. In other words, introverts were generally better readers than extroverts. This might be understandable if one puts the somewhat dominant paradigm of extroversion/introversion in context: extroverts outweigh introverts in amount of speech and discussion but they do not necessarily gain more than introverts when it comes to reading comprehension as students comprehend more of a reading text being exposed to the tasks that do not require that much of the others existence. Because it was revealed if introverts are tested on their own, they are perhaps not juxtaposed to a threat from others and may do their comprehension tasks individually and freely with less intrinsically-propelled intimidation of the others in the immediate environment.

\subsection{Pedagogical Implications}

Based on the findings of this study, it can be concluded that although previous studies mainly didn't support any of the models specifically (although without the consideration of personality type factors), the bottom-up processing can also 
be effective especially when dealing with various kinds of personality traits. The studies carried out earlier had mostly tried to show the effect of these goal structures on the overall achievement of learners in reading comprehension without paying much attention to learners' personality type.

The extroverts in this study enjoyed being in both groups but since they were more willing to be involved in discussion based and general activities rather than the activities which require careful attention for comprehension, they enjoyed top-down processing as it could be expected. The introverts, being the reserved type, did not produce that much and have tendency to do the activities for comprehension that can be done individually with great attention to details unless they were forced to and they were motivated by specifying some rewards for their production.

The setting of classes in Iran still follows somehow GTM or ALM, especially at the schools. For example, instead of working with a reading text in a top-down processing model and encouraging them to speak and discuss together about their own comprehension, they have a great tendency to remain focused a lot by paying attention to every single words, for example, for the sake of comprehension. In other words, students themselves are very interested in finding the meaning of unknown words from a dictionary or from teacher. The reason for this is that we have grown up more with the bottom-up processing culture than top-down processing culture. Therefore, for top-down processing model in reading comprehension to demonstrate its potential, ongoing cultural capacity building for practicing top-down processing model is required.

\section{References}

Abbot, G. (2007). The teaching of English as an international language. Glasgow and London: Collins.

Ajideh, P. (2003). Schemata theory-based pre-reading tasks: A neglected essential in the ESL reading class. The Reading Matrix, 3(1).

Barnett, M. A. (2007). Remembering: A study in experimental and social psychology. London: Cambridge University. Birch, B. M. (2007). English second language reading. Mahwah, NJ: Lawrence Erlbaum.

Boyle, G. J., Mathews, G., \& Saklofske, D. H. (2008). The sage handbook of personality theory and assessment. London: Sage Publications Ltd.

Brown, H. D. (2000). Principles of language learning and teaching. San Francisco: Addison Wesley Longman.

Brown, H. D. (2001). Teaching by principles: An Interactive Approach to Language Pedagogy. San Francisco: Addison Wesley Longman.

Celce- Murcia, M. (2001). Teaching English as a second of foreign language. Boston, MA: Heinle \& Heinle.

Chamorro-Premuzik, T. (2007). Personality and individual differences. Oxford: Blackwell.

Dornyei, Z. (2005). The psychology of the language learner. Individual differences in second language acquisition. Mahwah, NJ: Lawrence Erlbaum Associates.

Ellis, R. (2003). Task-based language teaching. Great Clarendon Street: Oxford University Press.

Eskey, D. E. (2005). Interactive models for second language. Oxford: Oxford University Press

Farstrup, S. (2002). What research has to say about reading instruction. Newark: DE: International Reading Association.

Gebhard, J. G. (2009). Teaching English as a second or foreign language. Ann Arbor, MI: University of Michigan Press.

Gladwin, F. R., \& Stepp-Greeny, J. (2008). An interactive, instructor supported reading approach vs. traditional reading instruction in Spanish. Foreign language annals, Vol. 41, No. 4.

Grabe, W. (2004). Research on teaching reading. Annual review of applied linguistics, 24, 44-69.

Hadley, A. O. (2003). Teaching language in context. Boston: Heinle \& Heinle

Harmer, J. (20008). How to teach English. Pearson Education Ltd.

Hedge, T. (2008). Teaching and learning in the language classroom. Oxford: Oxford University Press.

Mackey, A., Gass, S. (2005). Second language research: Methodology and design. NJ: LEA.

McNeil, J. D. (1992). Reading comprehension: New directions for classroom practice. Los Angeles, CA: University of California.

Naik, A. (2010). Introvert personality. Retrieved on July 10, 2010, from: WWW.buzzle.com/articles/introvertpersonality.html.

Nunan, D. (2001). Second Language teaching and learning. University of Hong Kong

Nuttal, C. (1998). Teaching reading skills in a foreign language. Oxford: McMillan.

Richards, J. C., \& Renandya, W. A. (2002). Methodology in language teaching. Cambridge: Cambridge University Press. 
Richards, J. C. \& Schmidt, R. W. (2002). Dictionary of language teaching and applied linguistics. NY \& London: Longman.

Roe, B. D., Smith, S. H., \& Burns, P. C. (2005). Teaching reading in today's elementary schools. Boston: Houghton Mifflin.

Rupp, A. A., Ferne, T., \& Choi, H. (2006). How assessing reading comprehension with multiple choice questions shapes the construct: A cognitive processing perspective. Humboldt University of Berlin: University of Ottawa.

Singh, B. (2005). Psychological foundations of education. New Delhi: Mehra Offset Press.

Snow, C. E. (2002). Reading for understanding: toward a research and development program in reading comprehension. Pittsburg: Rand.

Ur, P. (1996). A course in language teaching. Cambridge: Cambridge University Press. 